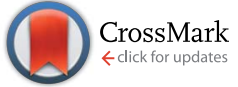

Cite this: J. Mater. Chem. C, 2014, 2 , 8277

Received 7th July 2014

Accepted 22nd August 2014

DOI: $10.1039 / \mathrm{c} 4 \mathrm{tc} 01467 \mathrm{~g}$

www.rsc.org/MaterialsC

\section{A versatile hybrid polyphenylsilane host for highly efficient solution-processed blue and deep blue electrophosphorescence $\uparrow$}

\author{
Dianming Sun, ${ }^{\text {a } X i a o k a n g ~ Z h o u, ~}{ }^{\mathrm{b}}$ Huihui Li, ${ }^{\text {a }}$ Xiaoli Sun, ${ }^{\text {a }}$ Yonghao Zheng, ${ }^{\mathrm{c}}$ \\ Zhongjie Ren, ${ }^{\star a}$ Dongge Ma, ${ }^{b}$ Martin R. Bryce*c and Shouke Yan*a
}

\begin{abstract}
A universal hybrid polymeric host (PCzSiPh) for blue and deep blue phosphors has been designed and synthesized by incorporating electron-donating carbazole as pendants on a polytetraphenylsilane main chain. The polymer PCzSiPh (4) has a wide bandgap and high triplet energy $\left(E_{T}\right)$ because of the tetrahedral geometry of the silicon atom in the tetraphenylsilane backbone. The distinct physical properties of good solubility, combined with high thermal and morphological stability give amorphous and homogenous PCzSiPh films by solution processing. As a result, using PCzSiPh as host with the guest iridium complex TMP-FIrpic gives blue phosphorescent organic light-emitting diodes (PhOLEDs) with overall performance which far exceeds that of a control device with poly(vinylcarbazole) (PVK) host. Notably, Flrpic-based devices exhibit a maximum external quantum efficiency (EQE) of $14.3 \%$ (29.3 cd $A^{-1}, 10.4 \mathrm{~lm} \mathrm{~W}^{-1}$ ) which are comparable to state-of-the-art literature data using polymer hosts for a blue dopant emitter. Moreover, the versatility of PCzSiPh extends to deep blue PhOLEDs using Flr6 and FCNIrpic as dopants, with high efficiencies of $11.3 \mathrm{~cd} \mathrm{~A}^{-1}$ and $8.6 \mathrm{~cd} \mathrm{~A}^{-1}$, respectively.
\end{abstract}

\section{Introduction}

Following the invention of the first practical organic light emitting diode (OLED), ${ }^{1}$ electrophosphorescent devices have drawn intense and sustained investigation for realizing the next generation full color displays and solid-state lighting applications because of their high quantum efficiency compared with conventional fluorescent OLEDs, which is achieved by utilizing both singlet and triplet excitons for emission. ${ }^{2-11}$ To achieve efficient electrophosphorescent OLEDs (PhOLEDs), emitters comprising heavy-metal complexes are usually dispersed into an appropriate host matrix to suppress concentration quenching and triplet-triplet annihilation. ${ }^{12}$ To date, green and red PhOLEDs with $100 \%$ internal quantum efficiency have been achieved, ${ }^{\mathbf{1 3}, \mathbf{1 4}}$ but highly efficient blue, and especially deep blue PhOLEDs remain to be further developed, primarily due to a lack of suitable host materials. An ideal host for blue PhOLEDs should possess sufficiently high triplet energy $\left(E_{\mathrm{T}}\right)(>2.7 \mathrm{eV})$ to confine triplet excitons within the emitting layer and avoid

${ }^{a}$ State Key Laboratory of Chemical Resource Engineering, Beijing University of Chemical Technology, Beijing 100029, China. E-mail: skyan@mail.buct.edu.cn; renzj@mail.buct.edu.cn

${ }^{b}$ State Key Laboratory of Polymer Physics and Chemistry, Changchun Institute of Applied Chemistry, Chinese Academy of Sciences, Changchun, 130022, China

'Department of Chemistry, Durham University, Durham, DH1 3LE, UK. E-mail: m.r. bryce@durham.ac.uk

† Electronic supplementary information (ESI) available. See DOI: $10.1039 / \mathrm{c} 4 \mathrm{tc} 01467 \mathrm{~g}$ reverse energy transfer from guest to host. In addition, the host should also possess high thermal, electrochemical, and morphological stability and good film-forming ability to achieve devices with high performance.

Many small-molecule hosts have been widely used to fabricate blue PhOLEDs, some of which perform very efficiently. ${ }^{15-23}$ However, these hosts are deposited by vacuum thermal evaporation, and thus high fabrication cost, device complexity, and control of reproducibility still hamper the practical applicability of blue PhOLEDs. In contrast, solution processing techniques, such as spin-coating and ink-jet printing, are cost-effective and convenient for simple device configurations, which are desirable for large-area devices such as flat panel displays. ${ }^{\mathbf{2 4 , 2 5}}$ Unlike small-molecule hosts, polymeric hosts allow easy manufacture of PhOLEDs through solution processing technology because of their good thermal and morphological stability and high affinity for substrates. New polymeric hosts for blue, and especially for deep blue PhOLEDs are currently very much in demand. ${ }^{26-31}$ In this context [bis(4,6-difluorophenyl)-pyridinato-N, $\mathrm{C}^{2}$ ]iridium(III) picolinate (Firpic) is the benchmark dopant for blue PhOLEDs. However, FIrpic has limited solubility in common organic solvents and is known to aggregate at high concentration. FIrpic devices have poor color stability and short lifetimes due to degradation of the complex. ${ }^{32}$ Thus, it is vital to develop polymeric hosts which are suitable for a wider range of blue emitting phosphors, such as [bis((3,5-difluorophenyl)-4-(2,4,6trimethylphenyl)pyridine)]iridium(III) picolinate (TMP-FIrpic), which is a blue dopant with good solubility for stable PhOLEDs 
at high doping concentration, ${ }^{33}$ and deep blue dopants, such as [bis(2,4-difluorophenylpyridinato)tetrakis(1-pyrazolyl)borate]iridium(III) (FIr6) and [bis((3,5-difluoro-4-cyanophenyl)pyridine)]iridium(III) picolinate (FCNIrpic).

Silica-based organic-inorganic hybrid materials have been studied for ideal host materials because of their advantages of very high thermal and chemical stabilities, good mechanical properties and high transparency, which are easily achieved by design of the organic and inorganic parts, respectively. ${ }^{34-39}$ For instance, phenylsilane and carbazole building blocks have been combined in a non-conjugated way to provide thermally-stable small-molecule hosts, ${ }^{\mathbf{4 0 - 4 2}}$ e.g. DPSiCBP (9-(4-(triphenylsilyl)phenyl)-9H-carbazole). Also DPSiCBP exerts a unique hindering effect on the molecular packing characteristics in the condensed phase. ${ }^{40}$

Herein, we successfully incorporate carbazole moieties as pendant groups into a polyphenylsilane chain to obtain a versatile polymeric host $\mathrm{PCzSiPh}$ (4) for several blue/deep blue emitting phosphors. The key molecular design features are as follows. Carbazole is a versatile unit in host molecules because it improves both hole injection and hole mobility. ${ }^{\mathbf{4 0 - 4 4}}$ Carbazole also has a high $E_{\mathrm{T}}$ of $3.0 \mathrm{eV}$. Importantly, the tetrahedral geometry of the silicon atom in tetraphenylsilane ensures limited $\pi$-conjugation between any two neighbouring carbazole pendants, which will maintain a high $E_{\mathrm{T}}$ value. Therefore, PCzSiPh prevents reverse energy transfer from guest to host. Moreover, $\mathrm{PCzSiPh}$ possesses a high degradation temperature, excellent film-forming ability and good compatibility with blue phosphors. We now report that blue and deep blue phosphorescent devices based on four phosphors have been assembled by solution processing of the single-emitter layer. Notably, PCzSiPh-based devices doped with TMP-FIrpic achieve significantly higher electroluminescence efficiency than directly comparable devices using the conventional poly(vinylcarbazole) (PVK) host. Moreover, all the blue and deep blue devices display excellent performance. Therefore, the new polyphenylsilane PCzSiPh (4) is demonstrated to be an outstanding and versatile host material for solution processed blue and deep blue PhOLEDs. We note that a polymeric host with a non-conjugated triphenylphosphine oxide backbone and pendant carbazole units has been used as a host for FIrpic; however, deep blue dopants were not reported. ${ }^{26}$

\section{Results and discussion}

\section{Synthesis and characterization}

The synthetic route and chemical structure of PCzSiPh (4) are depicted in Scheme 1. The silicon-containing skeleton tris(4bromophenyl)(phenyl)silane (1) was synthesized by lithiumhalogen exchange reaction and then the carbazole moiety was attached to form a dibromo-monomer (2) by a modified Ullmann $\mathrm{C}-\mathrm{N}$ coupling reaction in the presence of copper(I) iodide as a catalyst and (+/-)-trans-1,2-diaminocyclohexane as a ligand in dioxane. The diboronic ester (3), which is another key reagent for polymerization, was obtained from (2) with bis(pinacolato)diboron. PCzSiPh (4) was synthesized from the corresponding dibromo- and diboronic ester-monomers (2) and (3) through a

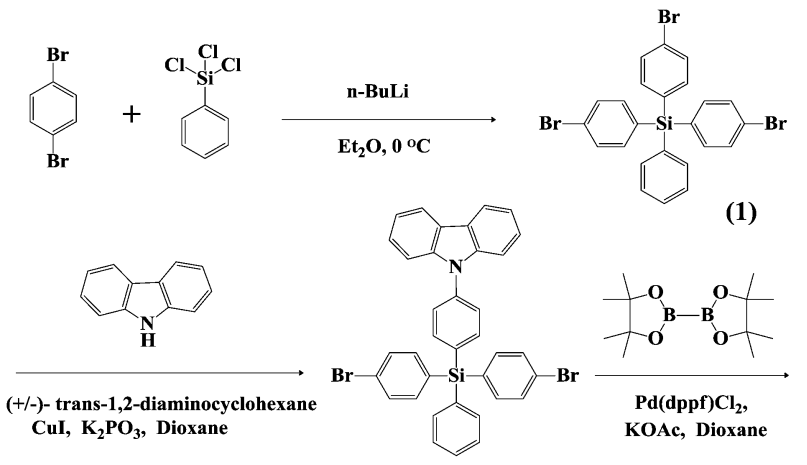

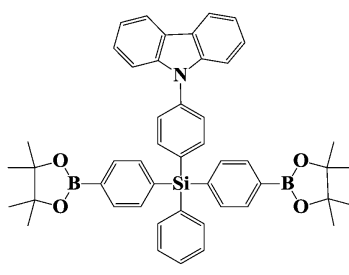

(3)

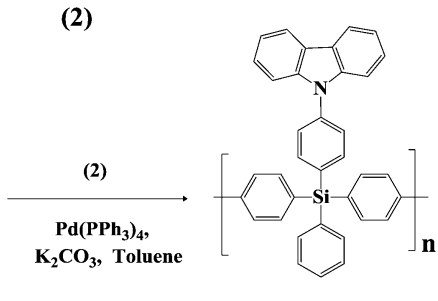

PCzSiPh (4)
Scheme 1 Synthetic route for PCzSiPh (4)

Suzuki coupling protocol. The resulting polymer (4) was obtained as a white solid. ${ }^{1} \mathrm{H}$ NMR, ${ }^{13} \mathrm{C}$ NMR, ${ }^{29} \mathrm{Si}$ NMR spectroscopies and mass spectrometry fully confirmed the chemical structures of the new compounds. Polymer (4) was characterized by ${ }^{1} \mathrm{H}$ NMR, ${ }^{29} \mathrm{Si}$ NMR spectroscopy and gel permeation chromatography (GPC). The weight average molecular weight was determined to be $13 \mathrm{kDa}$ with a narrow polydispersity index of 1.58 by GPC in THF using polystyrene as a standard. Additionally, PCzSiPh (4) is highly soluble in usual organic solvents such as chloroform, tetrahydrofuran, toluene and chlorobenzene. Therefore, it can be easily fabricated into films by casting, spin-coating, and dipping techniques.

\section{Thermal analysis}

The thermal properties of PCzSiPh (4) were investigated by thermogravimetric analysis (TGA) and differential scanning calorimetry (DSC) in nitrogen atmosphere at a heating rate of $10{ }^{\circ} \mathrm{C} \min ^{-1}$. The data are listed in Table 1 . PCzSiPh exhibits high thermal stability with decomposition temperature $\left(T_{\mathrm{d}}\right.$, corresponding to $5 \%$ weight loss) of $428{ }^{\circ} \mathrm{C}$ (Fig. 1a). The morphological stability of $\mathrm{PCzSiPh}$ was monitored by DSC which shows an endothermic transition due to a glass transition $\left(T_{\mathrm{g}}\right)$ at $118{ }^{\circ} \mathrm{C}$ for the second heating scan (Fig. 1b).

Table 1 Physical properties of PCzSiPh

\begin{tabular}{lllll}
\hline$E_{\mathrm{T}}{ }^{a}(\mathrm{eV})$ & $\mathrm{HOMO}^{b}(\mathrm{eV})$ & $\operatorname{LUMO}^{c}(\mathrm{eV})$ & $T_{\mathrm{g}}{ }^{d}\left({ }^{\circ} \mathrm{C}\right)$ & $T_{\mathrm{d}}{ }^{e}\left({ }^{\circ} \mathrm{C}\right)$ \\
\hline 2.79 & -5.65 & -2.08 & 118 & 428
\end{tabular}

${ }^{a}$ Triplet energy level. ${ }^{b}$ Highest occupied molecular orbital. ${ }^{c}$ Lowest unoccupied molecular orbital. ${ }^{d}$ Glass-transition temperature determined by DSC. ${ }^{e}$ Decomposition temperature determined by TGA at $5 \%$ weight loss. 

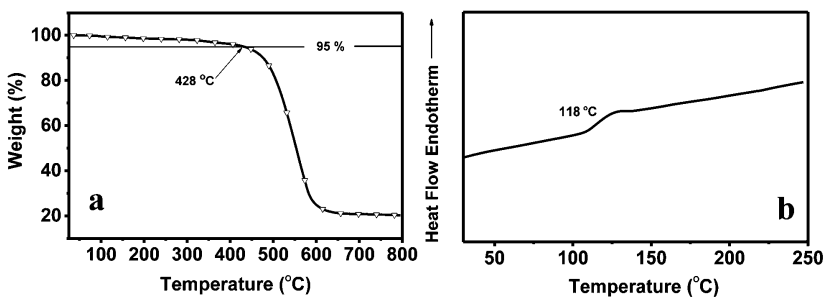

Fig. 1 (a) TGA trace of PCzSiPh recorded at a heating rate of $10^{\circ} \mathrm{C}$ min $^{-1}$ under nitrogen atmosphere; (b) DSC measurement recorded at a heating rate of $10{ }^{\circ} \mathrm{C} \mathrm{min}^{-1}$ under nitrogen atmosphere.

However, no exothermic peak due to crystallization nor an endothermic peak due to melting was observed over the investigated temperature range $\left(40-250{ }^{\circ} \mathrm{C}\right)$. These results indicate that PCzSiPh is a stable amorphous material. The $T_{g}$ value of $\mathrm{PCzSiPh}$ is significantly higher than that of corresponding monomer DPSiCBP (9-(4-(triphenylsilyl)phenyl)-9H-carbazole) $\left(T_{g}=71^{\circ} \mathrm{C}\right),{ }^{40}$ which should result from the steric hindrance of each pendant unit and the increased molecular size of PCzSiPh. Based on the excellent thermal and amorphous stabilities of $\mathrm{PCzSiPh}$, thermally durable and morphologically stable thin films and devices can be expected by spin-coating, which matches the basic requirement for host materials used in OLEDs.

\section{Film-forming ability}

To investigate the morphological stability of PCzSiPh as a host material, as well as compatibility with blue dopants (structures shown in Fig. 5), atomic force microscopy (AFM) was employed to image the surface of the solution-processed films of PCzSiPh doped with $10 \mathrm{wt} \%$ TMP-FIrpic, ${ }^{33} 10 \mathrm{wt} \%$ FIrpic, $10 \mathrm{wt} \%$ FIr6 and $3 \mathrm{wt} \%$ FCNIrpic, respectively. As shown in Fig. 2, all the
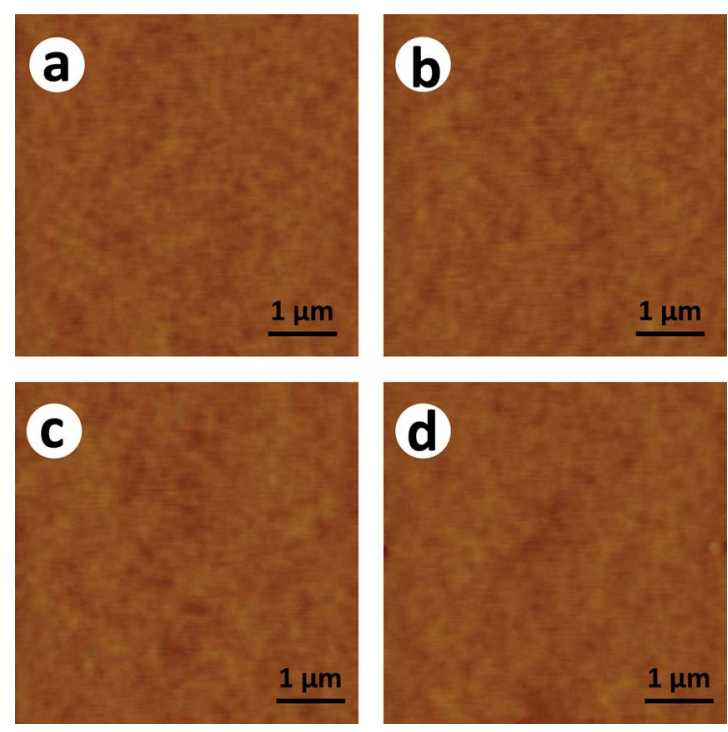

Fig. 2 AFM topographic images of the solution processed films from PCzSiPh doped with (a) 10 wt\% TMP-FIrpic; (b) 10 wt\% Flrpic; (c) 10 wt\% Flr6 and (d) 3 wt\% FCNIrpic. doped films show smooth and homogeneous morphologies, with small values of root-mean square (RMS) roughness of 0.47 $\mathrm{nm}$ for TMP-FIrpic, $0.42 \mathrm{~nm}$ for FIrpic, $0.49 \mathrm{~nm}$ for FIr6, 0.36 $\mathrm{nm}$ for FCNIrpic films, respectively. These results imply that the tetrahedral silicon configuration in $\mathrm{PCzSiPh}$ provides a stabilizing environment for dopants and should ensure that the structural integrity of the films is retained throughout the entire OLED fabrication process.

\section{Photophysical properties}

The UV-vis absorption spectrum of PCzSiPh in dilute dichloromethane (DCM) solution is presented in Fig. 3a. The peaks at around $293 \mathrm{~nm}$ and weaker absorption peaks at longer wavelengths of 326 and $340 \mathrm{~nm}$ are attributed to the $\pi-\pi^{*}$ transitions of extended conjugation of the carbazole moiety. In addition, a relatively wide energy gap $\left(E_{\mathrm{g}}\right)$ of $3.57 \mathrm{eV}$ is obtained from the onset of absorption.

As shown in Fig. 3a, the photoluminescence (PL) spectrum of PCzSiPh displays intense UV emission peaks at 351 and $363 \mathrm{~nm}$, compared with 4,4'-bis( $N$-carbazolyl)-1,1'-biphenyl (CBP) (372 $\mathrm{nm})$ a distinct higher energy emission is observed. The absorption and emission spectra of PCzSiPh are nearly identical to those of a previous phenylcarbazole-silane hybrid structure, ${ }^{36,40}$ suggesting that the polytetraphenylsilane backbone does not significantly influence the photophysical properties of the carbazole chromophores. The $E_{\mathrm{T}}$ of PCzSiPh was obtained from its phosphorescence spectrum in a frozen DCM solution at $77 \mathrm{~K}$ which reveals a well-structured band with main emission peaks at $\lambda_{\max } 444$ and $464 \mathrm{~nm}$ (Fig. 3a). An $E_{\mathrm{T}}$ of $2.79 \mathrm{eV}$ was calculated from the peak of the highest energy vibronic subband of this spectrum; this value is much higher than that of most commonly used phosphorescent dyes. The high $E_{\mathrm{T}}$ of PCzSiPh can be attributed to the disruption of $\pi$ conjugation caused by the tetrahedral silicon atom between each phenylcarbazole group within the polytetraphenylsilane main chain.

\section{Electrochemical analysis}

The electrochemical behavior of PCzSiPh was investigated by cyclic voltammetry (CV) using tetra( $n$-butyl)ammonium hexafluorophosphate $(0.1 \mathrm{M})$ as a supporting electrolyte in anhydrous DCM under a nitrogen atmosphere. In Fig. 3b, the CV shows an irreversible oxidation feature similar to other carbazole derivatives with unprotected 3,6-positions. The oxidation
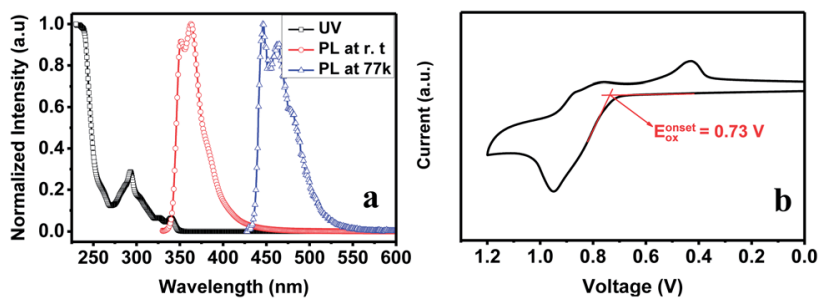

Fig. 3 (a) Room-temperature UV-vis absorption, photoluminescence $(\mathrm{PL})$ at room temperature and phosphorescence at $77 \mathrm{~K}$ spectra of $\mathrm{PCzSiPh}$ in DCM solution at $5 \times 10^{-6} \mathrm{M}$. (b) Cyclic voltammogram of $\mathrm{PCzSiPh}$ in DCM for the oxidation scan. 
onset potential is at $0.73 \mathrm{~V}$ versus $\mathrm{Ag} / \mathrm{Ag}^{+}$. As a result, the highest occupied molecular orbital (HOMO) energy level of PCzSiPh was calculated according to the empirical formula $E_{\mathrm{HOMO}}=-(4.8+$ $\left.E_{\mathrm{on}}{ }^{\text {ox }}-E_{\mathrm{Fc}}\right) \mathrm{eV}$. The lowest unoccupied molecular orbital (LUMO) energy level was obtained by adding the optical $E_{\mathrm{g}}$ to the HOMO level (as shown in Table 1). The HOMO level of PCzSiPh is $-5.65 \mathrm{eV}$, which is very similar to that of smallmolecule carbazole-silane derivatives. ${ }^{\mathbf{4 0 - 4 2}}$ This indicates that the HOMO of PCzSiPh is located mainly at the electron rich carbazole unit, and the backbone of the polymer does not affect the HOMO energy level.

\section{Theoretical calculations}

To understand the structure-property relationship of PCzSiPh at the molecular level, density functional theory (DFT) calculations were performed on a dimer model of PCzSiPh at the B3LYP/6-31G (d) theoretical level. The contour plots depicted in Fig. 4 show that the HOMO is localized on the carbazole group, while the LUMO is localized mainly on the polymer backbone. The almost complete separation of the HOMO and LUMO can be attributed to the silicon linkage between the 9-phenylcarbazole pendants and the backbone of $\mathrm{PCzSiPh}$ resulting in a minimal intramolecular interaction, which will not only benefit efficient hole- and electron-transporting properties, ${ }^{\mathbf{4 5}}$ but also renders the HOMO levels of host materials tunable by incorporating different donor pendants. ${ }^{46}$

\section{Phosphorescent OLEDs}

To evaluate the ability of PCzSiPh to act as a host material for solution-processed blue PhOLEDs, we first adopted the modified FIrpic with a trimethylphenyl (TMP) substituent (TMPFIrpic) $)^{33}$ as a blue phosphor to investigate the effect of different doping concentration. The device configuration is: indium tin oxide (ITO)/PEDOT:PSS (40 nm)/host:TMP-FIrpic (40-50 nm)/ 1,3,5-tri( $m$-pyrid-3-yl-phenyl)benzene (Tm3РyPB, $5 \mathrm{~nm}$ )/1,3,5tris(1-phenyl-1H-benzimidazol-2-yl)benzene (TPBi, $30 \mathrm{~nm}) / \mathrm{LiF}$ $(1 \mathrm{~nm}) / \mathrm{Al}(60 \mathrm{~nm})$. In this architecture, PEDOT:PSS acts as a hole injection layer, the emitting layer was spin-coating from chlorobenzene solution onto the PEDOT:PSS smoothed ITO glass substrate, and Tm3PyPB (ref. 47) and TPBi were used as the hole/exciton-blocking and electron-transporting layers, respectively. For each device, the host, dopant and dopant concentration are listed in Table 2. TMP-FIrpic has been shown to offer

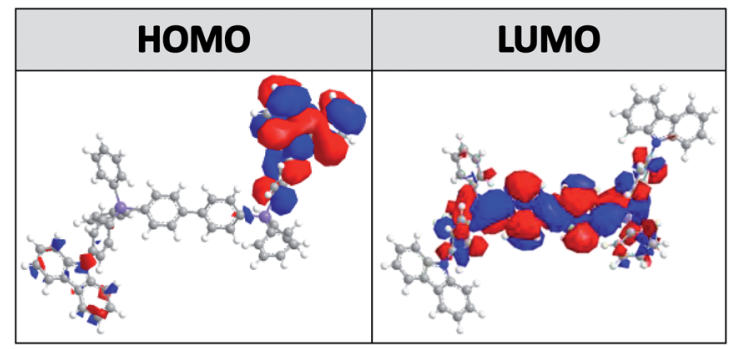

Fig. 4 Calculated spatial distributions of the HOMO and LUMO levels of a dimer model of PCzSiPh. significant advantages over FIrpic due to reduced concentration quenching and improved solubility in common solvents. ${ }^{33}$ For comparison, device 1 used a standard $10 \mathrm{wt} \%$ dopant concentration, whereas device 2 used an optimized $24 \mathrm{wt} \%$ TMP-FIrpic based on the literature precedent for this complex in PVK host. ${ }^{33}$

From luminance-voltage and current density-voltage characteristics (Fig. 6a and b) and efficiency versus current density curves (Fig. 6c and d) for devices 1 and 2, a striking improvement of luminance from 2613 to $3987 \mathrm{~cd} \mathrm{~m}^{-2}$, and luminance efficiency from 12.38 to $16.20 \mathrm{~cd} \mathrm{~A}^{-1}$ accompanies the increase in TMP-FIrpic loading. This is consistent with enhanced electron transporting ability and more balanced charge carrier flow in the emitting layer with increased TMP-FIrpic concentration. Meanwhile, for comparison, device 3 using PVK as the host at the concentration of $24 \mathrm{wt} \%$ TMP-FIrpic was also fabricated under precisely the same conditions as devices 1 and 2. The overall performance of the PVK-TMP-FIrpic device 3 was considerably lower than the analogous PCzSiPh host device 2.

Moreover, the EL spectra of PVK-host device 3 (Fig. 7c) broaden significantly with increasing voltage, while the spectra of the PCzSiPh-based device 2 are essentially independent of the applied voltage (Fig. 7b). This confirms that at the high dopant concentration $\mathrm{PCzSiPh}$ is more efficient than PVK at preventing dopant aggregation, which results in lower efficiency of PVKbased device 3 .

Moreover, compared with device 2, we removed the Tm3PyPB layer in device 4 to give the architecture of ITO/ PEDOT:PSS/PCzSiPh: 24 wt\% TMP-FIrpic (50 nm)/TPBi (30 nm)/ $\mathrm{LiF} / \mathrm{Al}$. The turn-on voltage decreased from $5.6 \mathrm{~V}$ to $5.2 \mathrm{~V}$ and the

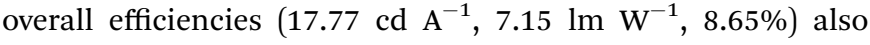
increased slightly which indicates that even without the Tm3PyPB hole/exciton-blocking layer $\mathrm{PCzSiPh}$ can efficiently confine triplet excitons within the emitting layer. This is further confirmed by the reduced broadening of the EL spectra (Fig. 7d) compared with that of PVK-based device 3 (Fig. 7c) which contains the hole/exciton-blocking layer. Our device architecture is a commonly-used optimized architecture for FIrpic, but may not be ideal for other FIrpic derivatives, which have different solubility in the casting solvents and different morphology in thin films.

The normalized electroluminance spectra of devices 1-4 are shown in Fig. 7 and the Commission International de I'Eclairage (CIE) coordinates are listed in Table 2. As clearly seen, except for the device 3 (Fig. 7c) based on PVK host with $\lambda_{\max }$ at $480 \mathrm{~nm}$, the other devices' spectra peak at $475 \mathrm{~nm}$, and their EL bands are nearly identical. Hence the EL originates only from the TMPFIrpic molecule, indicating an essentially complete energy or charge transfer from hosts to TMP-FIrpic. In addition, for PCzSiPh devices 1 and 2 no obvious CIE change can be seen with increasing voltages, whereas the CIE change for PVK device 3 from $(0.180,0.388)$ to $(0.218,0.416)$ is more obvious than that of device 4 from $(0.169,0.361)$ to $(0.182,0.376)$. These results unambiguously establish that PCzSiPh is a better host than PVK.

Based on the very promising performances of $\mathrm{PCzSiPh}$ as the host for TMP-FIrpic emitter and its high triplet energy level, $\mathrm{PCzSiPh}$ was also used as a universal host material for analogous blue (FIrpic) and deep blue phosphors, (FIr6 and 
Table 2 Device performance of PCzSiPh as host for blue and deep blue phosphor dopants

\begin{tabular}{|c|c|c|c|c|c|c|c|}
\hline Device no. & $1^{a}$ & $2^{a}$ & $3^{a}$ & $4^{b}$ & $5^{a}$ & $6^{a}$ & $7^{a}$ \\
\hline \multirow[t]{2}{*}{ Host } & PCzSiPh & $\mathrm{PCzSiPh}$ & PVK & $\mathrm{PCzSiPh}$ & $\mathrm{PCzSiPh}$ & PCzSiPh & PCzSiPh \\
\hline & $10 \mathrm{wt} \%$ & $24 \mathrm{wt} \%$ & $24 w t \%$ & $24 \mathrm{wt} \%$ & & & $3 \mathrm{wt} \%$ \\
\hline Dopant & TMP-FIrpic & TMP-FIrpic & TMP-FIrpic & TMP-FIrpic & 10 wt $\%$ FIrpic & 10 wt\% FIr6 & FCNIrpic \\
\hline$V_{\mathrm{on}}^{c}(\mathrm{~V})$ & 5.8 & 5.6 & 5.4 & 5.2 & 5.8 & 5.4 & 5.6 \\
\hline$L_{\max }{ }^{d}\left(\mathrm{~cd} \mathrm{~m}^{-2}\right)$ & 2613 & 3987 & 2303 & 4608 & 12421 & 5802 & 6951 \\
\hline$\eta_{\mathrm{c}, \max }{ }^{e}\left(\mathrm{~cd} \mathrm{\textrm {A } ^ { - 1 }}\right)$ & 12.38 & 16.20 & 10.62 & 17.77 & 29.3 & 11.3 & 8.56 \\
\hline$\eta_{\mathrm{p}, \max } f(\operatorname{lm} / \mathrm{W})$ & 5.55 & 6.21 & 5.38 & 7.15 & 10.4 & 4.8 & 2.80 \\
\hline$\eta_{\text {ext,max }}^{g}(\%)$ & 6.35 & 7.89 & 4.94 & 8.65 & 14.3 & 6.72 & 6.53 \\
\hline$V_{\text {appl }}^{h}(\mathrm{~V})$ & 7 & 8.2 & 6.2 & 7.8 & 8.8 & 7.4 & 9.6 \\
\hline $\operatorname{CIE}^{i}(x, y)$ & $0.155,0.347$ & $0.159,0.345$ & $0.180,0.388$ & $0.169,0.361$ & $0.149,0.322$ & $0.176,0.272$ & $0.143,0.181$ \\
\hline
\end{tabular}

${ }^{a}$ ITO/PEDOT:PSS/host:dopant (50 nm)/Tm3PyPB (5 nm)/TPBi (30 nm)/LiF/Al. ${ }^{b}$ ITO/PEDOT:PSS/host:dopant (50 nm)/TPBi (30 nm)/LiF/Al. ${ }^{c}$ Turnon voltage, recorded at a brightness of $1 \mathrm{~cd} \mathrm{~m}^{-2} .{ }^{d}$ Maximum luminance. ${ }^{e}$ Maximum current efficiency. ${ }^{f}$ Maximum power efficiency. ${ }^{g}$ Maximum external quantum efficiency. ${ }^{h}$ Applied voltage for maximum efficiency. ${ }^{i}$ Commission International de I'Eclairage (CIE) coordinates at turn-on voltage.

FCNIrpic) (Fig. 5). These devices 5-7 have the same configuration as device 1. Fig. 8a-d depict the current density-voltage, brightness-voltage characteristics and device efficiencies. Table
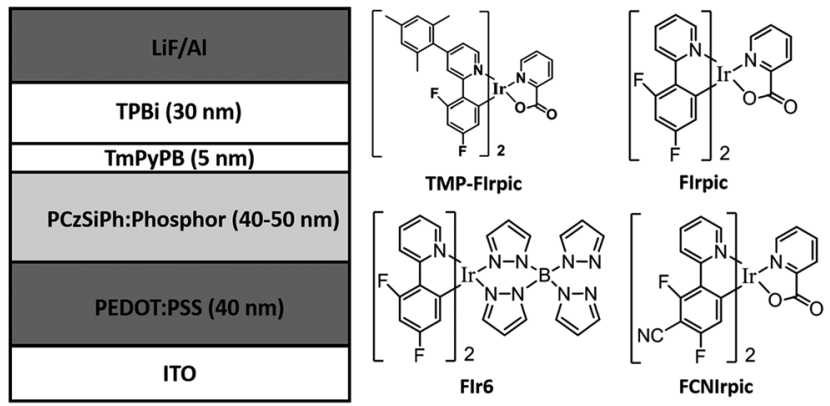

Fig. 5 Device structure and the corresponding materials used in these devices.
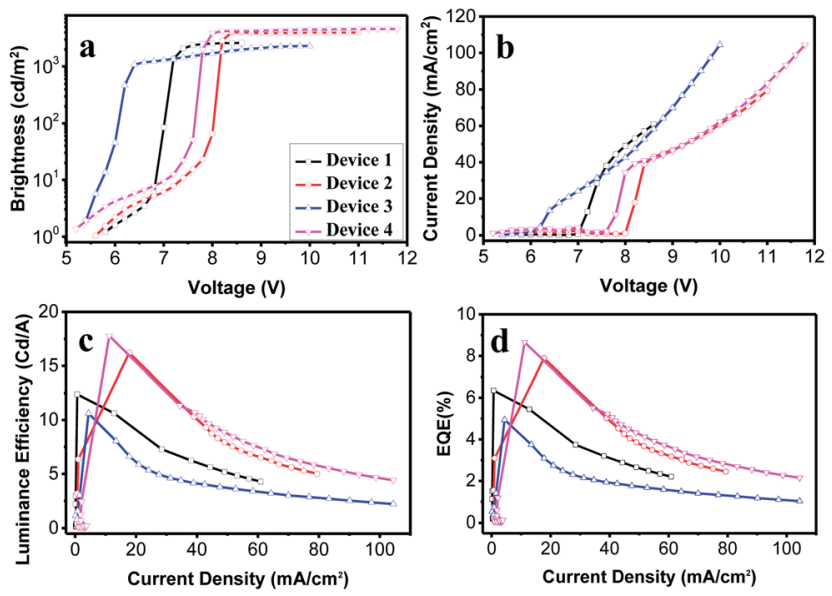

Fig. 6 (a) J-V characteristics; (b) $L-V$ characteristics; (c) current efficiency versus current density characteristics and (d) external quantum efficiency versus current density of TMP-FIrpic doped devices 1-4 (see Table 2).
2 summarizes the electroluminescence data. The blue and deep blue devices 5-7 possess relatively low turn-on voltages of 5.4$5.8 \mathrm{~V}$ and maximum brightness from 5800 to $12400 \mathrm{~cd} \mathrm{~m}^{-2}$ with CIE coordinates of $(0.149,0.322)$ for FIrpic, $(0.176,0.272)$ for FIr6 and $(0.143,0.181)$ for FCNIrpic. The best EL performance was achieved for the FIrpic device 5 with $\mathrm{CE}_{\max }$ of $29.3 \mathrm{~cd}$ $\mathrm{A}^{-1}, \mathrm{PE}_{\max }$ of $10.4 \mathrm{~lm} \mathrm{~W}^{-1}$, and $\mathrm{EQE}_{\max }$ of $14.3 \%$. These values indicate that spin-coated PCzSiPh:FIrpic-based devices exceed the highest values reported for solution-processed FIrpic devices $\left(23.3 \mathrm{~cd} \mathrm{~A} \mathrm{~A}^{-1}, 10.8 \%\right),{ }^{26}$ and even compete with the more complicated device architectures, such as the incorporation of TAPC as electron-blocking layer via a solution process, ${ }^{48}$ a double-emission-layer structured device ${ }^{49}$ and a mixed host system. ${ }^{50}$ The EL spectra of devices employing these phosphors are shown in Fig. S1. $\dagger$ All show the same main emission peak as literature reports for these phosphors and they demonstrate good color stability at different voltages.

To further investigate the exciton confinement, the transient photoluminescence decay of different phosphors doped into

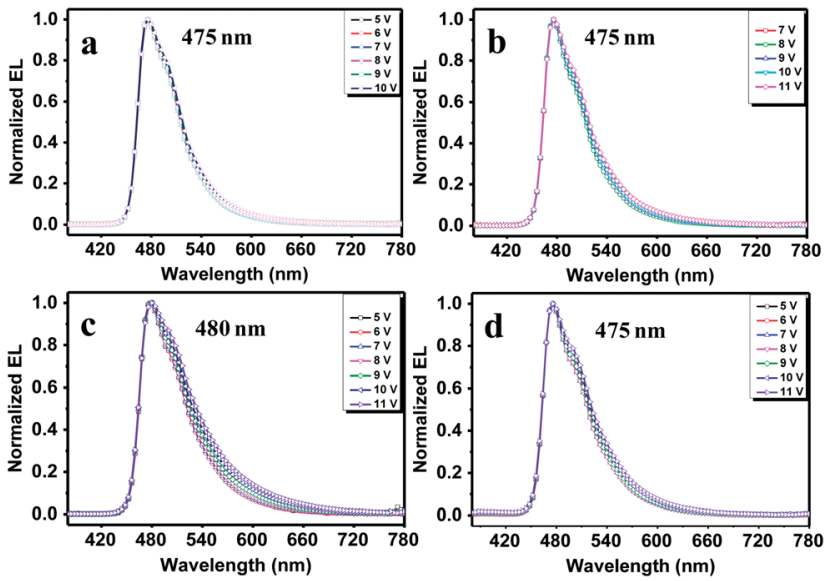

Fig. 7 Voltage dependent electroluminance spectra of (a) device 1; (b) device 2; (c) device 3 and (d) device 4. 

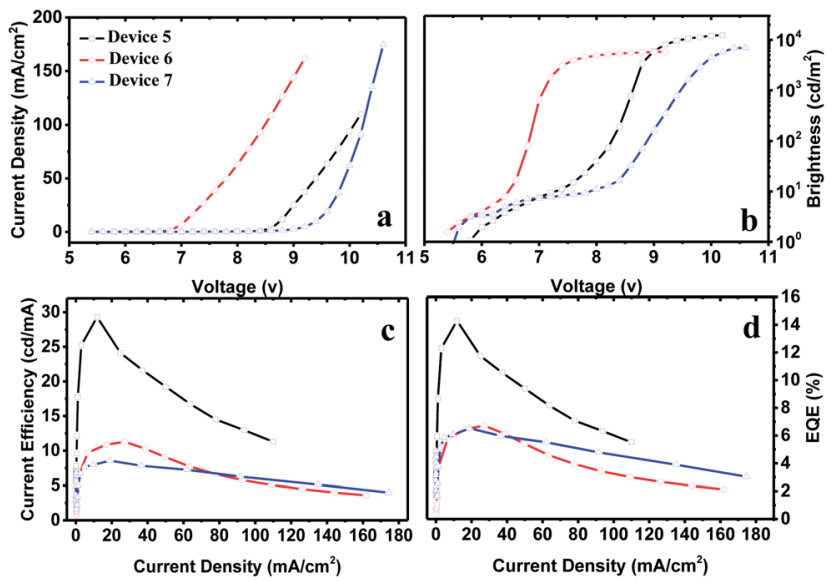

Fig. 8 (a) Current density-voltage characteristics; (b) brightnessvoltage characteristics; (c) current efficiency-current density characteristics and (d) external quantum efficiency-current density characteristics for devices $5-7$.

PCzSiPh was measured (Fig. S13†). The PCzSiPh: 3 wt\% FCNIrpic film exhibits a complicated non-exponential decay curve, which can be attributed to the exothermic energy transfer from FCNIrpic to PCzSiPh and the endothermic energy transfer to FCNIrpic. This may induce triplet exciton quenching by the emitting layer for FCNIrpic-based deep blue phosphorescent OLEDs, and thus a sharply decreased performance compared with that of the FIrpic-based device. The transient decay of the PCzSiPh: 10 wt\% FIr6 film is not monoexponential. PCzSiPh: 10 wt\% FIrpic film exhibits a more approximate monoexponential decay curve than that of PCzSiPh: 10 wt $\%$ TMP-FIrpic film, indicating that the triplet energy transfer from FIrpic to $\mathrm{PCzSiPh}$ is completely suppressed and the energy is well confined on the FIrpic molecules. This will lead to the observed highly efficient blue phosphorescent OLEDs.

\section{Experimental section}

\section{Materials}

All reactants (Adamas-beta) were purchased from Adamas Reagent, Ltd. and used without further purification. All solvents were supplied by Beijing Chemical Reagent Co., Ltd. Anhydrous and deoxygenated solvents were obtained by distillation over sodium benzophenone complex.

\section{Molecular simulation}

The geometrical and electronic property was carried out on the dimer of PCzSiPh with the Gaussian 09 program package. The molecular orbitals were calculated by the density functional theory (DFT) method at the B3LYP level with the 6-31G(d) atomic basis set.

\section{Device fabrication}

The hole-injection material PEDOT:PSS, electron-transporting material TPBi and hole/exciton-blocking material Tm3PyPB were used from commercial sources. ITO-coated glass with a sheet resistance of $10 \Omega$ per square was used as the substrate. Before device fabrication, the ITO-coated glass substrate was pre-cleaned carefully and exposed to UV-ozone for $2 \mathrm{~min}$. After that, PEDOT:PSS was spin-coated onto the clean ITO substrate as a hole-injection layer. Then, the host doped with the phosphor was spin-coated to form a $40 \mathrm{~nm}$ thick emissive layer (EML) and annealed at $120{ }^{\circ} \mathrm{C}$ for $30 \mathrm{~min}$ to remove residual solvent. Finally a $5 \mathrm{~nm}$-thick hole/exciton-blocking layer of Tm3PyPB and a $30 \mathrm{~nm}$-thick electron-transporting layer (ETL) of TPBi were vacuum deposited, and a cathode composed of a 1 $\mathrm{nm}$-thick layer of lithium fluoride (LiF) and aluminum (60 nm) were sequentially deposited onto the substrate through shadow masking with a pressure of $10^{-6}$ Torr. The current densityvoltage-luminance $(J-V-L)$ characteristic of the device was measured using a Keithley 2400 Source meter and a Keithley 2000 Source multimeter equipped with a calibrated Si-photodiode in a glove box. The EL spectra were measured using a JY SPEX CCD 3000 spectrometer. The EQE values were calculated from the luminance, current density, and electroluminescence spectrum according to standard methods. All measurements were performed at room temperature under ambient conditions.

\section{Characterization}

${ }^{1} \mathrm{H}$ NMR ${ }^{13} \mathrm{C}$ NMR and ${ }^{29} \mathrm{Si}$ NMR spectra were recorded on a Bruker AV400 (400 MHz) spectrometer. Chemical shifts $(\delta)$ are given in parts per million ( $\mathrm{ppm}$ ) relative to tetramethylsilane (TMS; $\delta=0$ ) as the internal reference. ${ }^{1} \mathrm{H}$ NMR spectra data are reported as chemical shift, relative integral, multiplicity ( $\mathrm{s}=$ singlet, $\mathrm{d}=$ doublet, $\mathrm{m}=$ multiplet $)$, coupling constant $(\mathrm{J}$ in $\mathrm{Hz}$ ) and assignment. UV-vis absorption spectra were recorded on a Shimadzu UV-3600 recording spectrophotometer. PL spectra were recorded on a Hitachi F-7000 fluorescence spectrophotometer. Differential scanning calorimetry (DSC) was performed on a TA Q2000 Differential Scanning Calorimeter at a heating rate of $10{ }^{\circ} \mathrm{C} \mathrm{m^{-1 }}$ from 30 to $250{ }^{\circ} \mathrm{C}$ under nitrogen atmosphere. The glass transition temperature $\left(T_{\mathrm{g}}\right)$ was determined from the second heating scan. Thermogravimetric analysis (TGA) was undertaken with a METTLER TOLEDO TGA/DSC 1/1100SF instrument. The thermal stability of the samples under a nitrogen atmosphere was determined by measuring their weight loss while heating at a rate of $10{ }^{\circ} \mathrm{C} \mathrm{min}{ }^{-1}$ from 30 to $800{ }^{\circ} \mathrm{C}$. Cyclic voltammetry $(\mathrm{CV})$ was carried out in nitrogenpurged dichloromethane (oxidation scan) at room temperature with a CHI voltammetric analyzer. Tetrabutylammonium hexafluorophosphate $\left(\mathrm{TBAPF}_{6}\right)(0.1 \mathrm{M})$ was used as the supporting electrolyte. The conventional three-electrode configuration consists of a glassy carbon working electrode, a platinum wire auxiliary electrode, and an $\mathrm{Ag} / \mathrm{AgNO}_{3}$ pseudo-reference electrode with ferrocenium-ferrocene $\left(\mathrm{Fc}^{+} / \mathrm{Fc}\right)$ as the internal standard. Cyclic voltammograms were obtained at scan rate of $100 \mathrm{mV} \mathrm{s}^{-1}$. The onset potential was determined from the intersection of two tangents drawn at the rising and background current of the cyclic voltammogram. Gel permeation chromatography (GPC) analysis was carried out on a Waters 515-2410 system using polystyrene standards as molecular 
weight references and tetrahydrofuran (THF) as the eluent. The morphologies and thickness of the polymer films coated on the ITO substrate was measured using atomic force microscopy (Agilent-5500 AFM) under tapping mode. The ESI-MS spectra were recorded in positive ion mode on Xevo G2 QTof mass spectrometer (Waters, Manchester, UK).

\section{Synthetic procedures}

Tris(4-bromophenyl)(phenyl)silane (1). 1,4-Dibromobenzene $(42.5 \mathrm{~g}, 180 \mathrm{mmol})$ was dissolved in dry diethyl ether $(250 \mathrm{~mL})$ and cooled to $0{ }^{\circ} \mathrm{C}$ in an ice/water bath. To the solution was added $n$-BuLi (1.6 M, $120 \mathrm{~mL}, 1.05$ equiv.) dropwise via a syringe. After being stirred for $1 \mathrm{~h}$, trichlorophenylsilane (9.6 $\mathrm{mL}, 60 \mathrm{mmol}$ ) was added dropwise. Then the reaction mixture was warmed to room temperature and stirred overnight. The reaction mixture was then poured into water and extracted with diethyl ether. The combined organic solution was washed with water and dried over anhydrous $\mathrm{Na}_{2} \mathrm{SO}_{4}$. The crude product was purified by recrystallization in ethanol as colorless crystals (29.6 g, 86\% yield). ${ }^{1} \mathrm{H}$ NMR (400 MHz, $\left.\mathrm{CDCl}_{3}, \delta\right): 7.57$ (d, $J=8 \mathrm{~Hz}, 6 \mathrm{H}$; Ar H), 7.51 (t, $J=7 \mathrm{~Hz}, 3 \mathrm{H}$; Ar H), 7.44 (d, $J=8$ $\mathrm{Hz}, 2 \mathrm{H}$; Ar H), 7.41 (d, $J=8 \mathrm{~Hz}, 6 \mathrm{H}$; $\mathrm{Ar} \mathrm{H}) ;{ }^{13} \mathrm{C}$ NMR $(400 \mathrm{MHz}$, $\left.\mathrm{CDCl}_{3}, \delta\right): 137.7,136.2,132.5,132.1,131.4,130.3$, 128.3, 125.3; ${ }^{29} \mathrm{Si} \mathrm{NMR}\left(400 \mathrm{MHz}, \mathrm{CDCl}_{3}, \delta\right):-13.81$.

9-(4-(Bis(4-bromophenyl)(phenyl)silyl)phenyl)-9H-carbazole (2). A mixture of tris(4-bromophenyl)(phenyl)silane (1) (23 g, 40 $\mathrm{mmol}$ ), carbazole (6.68 g, $40 \mathrm{mmol})$, $\mathrm{CuI}(0.4 \mathrm{~g}, 2 \mathrm{mmol}), \mathrm{K}_{3} \mathrm{PO}_{4}$ $(17 \mathrm{~g}, 80 \mathrm{mmol})$, and $( \pm)$-trans-1,2-diaminocyclohexane (0.46 g, $4 \mathrm{mmol})$ was added to 1,4-dioxane $(200 \mathrm{~mL})$, then refluxed under nitrogen for $24 \mathrm{~h}$. After cooling, the reaction mixture was quenched with $\left(\mathrm{NH}_{4}\right)_{2} \mathrm{CO}_{3}$ solution and extracted with $\mathrm{CH}_{2} \mathrm{Cl}_{2}$, then dried over anhydrous $\mathrm{MgSO}_{4}$. After removal of the solvent, the residue was purified by column chromatography on silica gel using petroleum/dichloromethane $(10: 1 \mathrm{v} / \mathrm{v})$ as the eluent, followed by recrystallization with $\mathrm{CH}_{2} \mathrm{Cl}_{2}$ and ethanol to give a white powder in $57 \%$ yield $(15 \mathrm{~g}) .{ }^{1} \mathrm{H} \mathrm{NMR}\left(400 \mathrm{MHz}, \mathrm{CDCl}_{3}, \delta\right)$ : 8.19 (d, $J=8 \mathrm{~Hz}, 2 \mathrm{H}$; Ar H), 7.80 (d, $J=8 \mathrm{~Hz}, 2 \mathrm{H} ; \mathrm{Ar} \mathrm{H}), 7.67$ (q, $J$ $=8 \mathrm{~Hz}, 8 \mathrm{H} ; \mathrm{Ar} \mathrm{H}), 7.52(\mathrm{t}, J=7 \mathrm{~Hz}, 11 \mathrm{H} ; \mathrm{Ar} \mathrm{H}), 7.33(\mathrm{t}, J=7 \mathrm{~Hz}$, $2 \mathrm{H} ; \mathrm{Ar} \mathrm{H}) ;{ }^{13} \mathrm{C}$ NMR (400 MHz, $\mathrm{CDCl}_{3}, \delta$ ): 140.5, 139.4, 137.8, 136.2 , 132.7, 132.3, 131.4, 130.2, 128.3, 126.3, 125.9, 125.2, 123.6, 120.4, 109.8; MS (ESI) $m / z$ : $[\mathrm{M}+\mathrm{H}]^{+}$calcd for $\mathrm{C}_{36} \mathrm{H}_{25^{-}}$ $\mathrm{Br}_{2} \mathrm{NSi}$, 660.4960; found, 660.3872.

9-(4-(Phenylbis(4-(4,4,5,5-tetramethyl-1,3,2-dioxaborolan-2-yl)phenyl)silyl)phenyl)-9H-carbazole (3). A mixture of 9-(4-(bis(4bromophenyl)(phenyl)silyl)phenyl)-9H-carbazole (2) (3.29 g, 5 $\mathrm{mmol}$ ), bis(pinacolato)diboron (3.81 g, $15 \mathrm{mmol})$, [1,10-bis(diphenylphosphino)ferrocene]palladium(II) dichloride $(0.3 \mathrm{~g}, 0.4$ $\mathrm{mmol})$, potassium acetate $(3 \mathrm{~g}, 30 \mathrm{mmol})$, and DMF $(50 \mathrm{~mL})$ was stirred at $80{ }^{\circ} \mathrm{C}$ for 5 days. $\mathrm{CH}_{2} \mathrm{Cl}_{2}$ was added to the reaction mixture, and the organic layer was washed with $\mathrm{H}_{2} \mathrm{O}$ and brine and dried over $\mathrm{Na}_{2} \mathrm{SO}_{4}$. After evaporation of the solvent, the residue was purified by column chromatography on silica gel using petroleum/dichloromethane $(6: 1 \mathrm{v} / \mathrm{v})$ as the eluent to give a white powder (2.5 g, 67\% yield). ${ }^{1} \mathrm{H} \mathrm{NMR}\left(400 \mathrm{MHz}, \mathrm{CDCl}_{3}, \delta\right)$ : 8.21 (d, $J=8 \mathrm{~Hz}, 2 \mathrm{H}$; Ar H), 8.00 (d, $J=8 \mathrm{~Hz}, 4 \mathrm{H}$; Ar H), 7.90 (d, $J=$ $8 \mathrm{~Hz}, 2 \mathrm{H}$; Ar H), 7.80 (q, $=7 \mathrm{~Hz}, 6 \mathrm{H} ; \mathrm{Ar} \mathrm{H}), 7.68$ (t, $J=7 \mathrm{~Hz}, 3 \mathrm{H}$;
Ar H), 7.60 (m, 8H; Ar H), 7.37 (t, $J=7 \mathrm{~Hz}, 2 \mathrm{H}$; Ar H), 1.44 (s, 24H; $\left.-\mathrm{CH}_{3}\right) ;{ }^{13} \mathrm{C} \mathrm{NMR}\left(400 \mathrm{MHz}, \mathrm{CDCl}_{3}, \delta\right): 139.1,138.0,137.3,136.5$, 135.8, 134.2, 133.6, 130.0, 128.2, 126.2, 123.6, 120.4, 109.9, 83.9, 25.1; ${ }^{29} \mathrm{Si} \mathrm{NMR} \mathrm{(400} \mathrm{MHz,} \mathrm{CDCl}_{3}, \delta$ ): -14.36; MS (ESI) $m / z:[\mathrm{M}+$ $\mathrm{H}]^{+}$calcd for $\mathrm{C}_{48} \mathrm{H}_{49} \mathrm{~B}_{2} \mathrm{NO}_{4} \mathrm{Si}, 754.6280$; found, 754.3707.

PCzSiPh (4). In a $50 \mathrm{~mL}$ round flask, a mixture of monomers (2) $(1.32 \mathrm{~g}, 2.0 \mathrm{mmol})$ and (3) (1.51 g, $2.0 \mathrm{mmol}),\left[\left(\mathrm{PPh}_{3}\right)_{4}\right] \mathrm{Pd}(0)$ $(1 \mathrm{~mol} \%, 23 \mathrm{mg})$, toluene $(1.2 \mathrm{~mL})$ and aqueous $\mathrm{K}_{2} \mathrm{CO}_{3}(2 \mathrm{M}, 0.8$ $\mathrm{mL}$ ) was stirred at $85{ }^{\circ} \mathrm{C}$ for 3 days under nitrogen atmosphere. After cooling to room temperature, the mixture was extracted, concentrated, and the polymer (4) was precipitated from methanol and obtained as a white solid (1.22 g, 61\% yield). ${ }^{1} \mathrm{H}$ NMR (400 MHz, $\mathrm{CDCl}_{3}, \delta$ ): 8.12 (br s, 4H, Ar H), 7.77 (br s, 4H; Ar $\mathrm{H}), 7.24$ (br s, $17 \mathrm{H}$; Ar H); ${ }^{29} \mathrm{Si} \mathrm{NMR}\left(400 \mathrm{MHz}, \mathrm{CDCl}_{3}, \delta\right):-21.88$. GPC (RI, polystyrene calibration) $M_{\mathrm{w}}=13 \mathrm{kDa}, M_{\mathrm{w}} / M_{\mathrm{n}}=1.58$.

\section{Conclusions}

In summary, a solution-processable polymer with a tetraphenylsilane repeat unit and pendant carbazole units has been synthesized and characterized. The tetrahedral tetraphenylsilane geometry is effective for ensuring the separation of carbazole units, and reducing $\pi-\pi$ face-to-face electronic interactions in the polymer. Thus, PCzSiPh exhibits the desirable properties of excellent solubility, high thermal and morphological stability, independent HOMO and LUMO levels at carbazole pendants and polymer backbone, respectively, and a high triplet energy level. Furthermore, the extended molecular size improves the solution processability and thermal stability in comparison with the corresponding (single repeat unit) smallmolecule analog DPSiCBP, without lowering the triplet energies or affecting the electron properties. As a result, PCzSiPh gives solution-processed PhOLEDs with the guest emitter TMP-FIrpic which displays considerably higher efficiency than comparable devices with PVK host. This can be attributed to the high triplet energy $(2.79 \mathrm{eV})$ of PCzSiPh and its ability to confine triplet excitons on the guest, and its good solution processability forming films with smooth and homogeneous morphology. Moreover, the FIrpic-based device reaches a maximum external quantum efficiency (EQE) of $14.3 \%$ which is among the most efficient reported using polymer hosts. We especially note that the versatility of PCzSiPh has been extended to deep blue PhOLEDs based on FIr6 and FCNIrpic as emitters with efficiencies of $11.3 \mathrm{~cd} \mathrm{~A}^{-1}$ and $8.6 \mathrm{~cd} \mathrm{~A}^{-1}$, respectively. These results indicate that $\mathrm{PCzSiPh}$ with its high triplet energy has great potential applications as a host in manufacturing highly efficient solution-processed blue and deep blue OLEDs for display and lighting applications.

\section{Acknowledgements}

The financial supports of NSFC (21104002 \& 51221002) and Beijing Higher Education Young Elite Teacher Project (YETP0491) are gratefully acknowledged. Z. R. thanks the China Scholarship Council for funding a visit to Durham University. 


\section{Notes and references}

1 C. Tang and S. VanSlyke, Appl. Phys. Lett., 1987, 51, 913.

2 H. Kanno, K. Ishikawa, Y. Nishio, A. Endo, C. Adachi and

K. Shibata, Appl. Phys. Lett., 2007, 90, 123509.

3 H. Sasabe, N. Toyota, H. Nakanishi, T. Ishizaka, Y. J. Pu and J. Kido, Adv. Mater., 2012, 24, 3212.

4 B. W. D'Andrade, J. Esler, C. Lin, V. Adamovich, S. Xia, M. S. Weaver, R. Kwong and J. J. Brown, Proc. SPIE, 2008, 7051, 70510Q.

5 Y. Seino, H. Sasabe, Y. J. Pu and J. Kido, Adv. Mater., 2014, 10, 1612.

6 H. Sasabe, Y. Seino, M. Kimura and J. Kido, Chem. Mater., 2012, 24, 1404.

7 H. H. Chou and C. H. Cheng, Adv. Mater., 2010, 22, 2468.

8 Y. C. Zhu, L. Zhou, H. Y. Li, Q. L. Xu, M. Y. Teng, Y. X. Zheng, J. L. Zuo, H. J. Zhang and X. Z. You, Adv. Mater., 2011, 23, 4041.

9 Y. J. Cho, K. S. Yook and J. Y. Lee, Adv. Mater., 2014, 26, 4050.

10 H. Sasabe, H. Nakanishi, Y. Watanabe, S. Yano, M. Hirasawa, Y. J. Pu and J. Kido, Adv. Funct. Mater., 2013, 23, 5550.

11 X. Wang, S. Wang, Z. Ma, J. Ding, L. Wang, X. Jing and F. Wang, Adv. Funct. Mater., 2014, 24, 3413.

12 M. A. Baldo, C. Adachi and S. R. Forrest, Phys. Rev. B: Condens. Matter Mater. Phys., 2000, 62, 10967.

13 Y. Kawamura, K. Goushi, J. Brooks, J. J. Brown, H. Sasabe and C. Adachi, Appl. Phys. Lett., 2005, 86, 071104.

14 C. Adachi, M. A. Baldo, M. E. Thompson and S. R. Forrest, J. Appl. Phys., 2001, 90, 5048.

15 C. W. Lee and J. Y. Lee, Adv. Mater., 2013, 25, 596.

16 H. Liu, G. Cheng, D. Hu, F. Shen, Y. Lv, G. Sun, B. Yang, P. Lu and Y. Ma, Adv. Funct. Mater., 2012, 22, 2830.

17 C.-J. Zheng, J. Ye, M.-F. Lo, M.-K. Fung, X.-M. Ou, X.-H. Zhang and C.-S. Lee, Chem. Mater., 2012, 24, 643.

18 H. Fukagawa, N. Yokoyama, S. Irisa and S. Tokito, Adv. Mater., 2010, 22, 4775.

19 P. Schrögel, M. Hoping, W. Kowalsky, A. Hunze, G. Wagenblast, C. Lennartz and P. Strohriegl, Chem. Mater., 2011, 23, 4947.

20 D. Wagner, S. T. Hoffmann, U. Heinemeyer, I. Münster, A. Köhler and P. Strohriegl, Chem. Mater., 2013, 25, 3758.

21 J. Ding, Q. Wang, L. Zhao, D. Ma, L. Wang, X. Jing and F. Wang, J. Mater. Chem., 2010, 20, 8126.

22 D. Kim, L. Zhu and J.-L. Brédas, Chem. Mater., 2012, 24, 2604.

23 C.-H. Yang, M. Mauro, F. Polo, S. Watanabe, I. Muenster, R. Fröhlich and L. De Cola, Chem. Mater., 2012, 24, 3684.

24 M. Cai, T. Xiao, E. Hellerich, Y. Chen, R. Shinar and J. Shinar, Adv. Mater., 2011, 23, 3590.

25 A. C. Arias, J. D. MacKenzie, I. McCulloch, J. Rivnay and A. Salleo, Chem. Rev., 2010, 110, 3.

26 S. Shao, J. Ding, T. Ye, Z. Xie, L. Wang, X. Jing and F. Wang, Adv. Mater., 2011, 23, 3570.

27 Y. Zhang, C. Zuniga, S.-J. Kim, D. Cai, S. Barlow, S. Salman, V. Coropceanu, J.-L. Brédas, B. Kippelen and S. Marder, Chem. Mater., 2011, 23, 4002.
28 S. Shao, J. Ding, L. Wang, X. Jing and F. Wang, J. Am. Chem. Soc., 2012, 134, 15189.

29 B. Zhang, G. Tan, C. S. Lam, B. Yao, C. L. Ho, L. Liu, Z. Xie, W. Y. Wong, J. Ding and L. Wang, Adv. Mater., 2012, 24, 1873. 30 J. H. Park, T.-W. Koh, J. Chung, S. H. Park, M. Eo, Y. Do, S. Yoo and M. H. Lee, Macromolecules, 2013, 46, 674.

31 D. Sun, Q. Fu, Z. Ren, W. Li, H. Li, D. Ma and S. Yan, J. Mater. Chem. C, 2013, 1, 5344.

32 V. Sivasubramaniam, F. Brodkorb, S. Hanning, H. P. Loebl, V. van Elsbergen, $H$. Boerner, U. Scherf and M. Kreyenschmidt, J. Fluorine Chem., 2009, 130, 640.

33 V. N. Kozhevnikov, Y. Zheng, M. Clough, H. A. Al-Attar, G. C. Griffiths, K. Abdullah, S. Raisys, V. Jankus, M. R. Bryce and A. P. Monkman, Chem. Mater., 2013, 25, 2352.

34 S. Gong, Q. Fu, Q. Wang, C. Yang, C. Zhong, J. Qin and D. Ma, Adv. Mater., 2011, 23, 4956.

35 J.-H. Jou, W.-B. Wang, S.-Z. Chen, J.-J. Shyue, M.-F. Hsu, C.-W. Lin, S.-M. Shen, C.-J. Wang, C.-P. Liu, C.-T. Chen, M.-F. Wu and S.-W. Liu, J. Mater. Chem., 2010, 20, 8411.

36 W. S. Han, H. J. Son, K. R. Wee, K. T. Min, S. Kwon, I. H. Suh, S. H. Choi, D. H. Jung and S. O. Kang, J. Phys. Chem. C, 2009, 113, 19686.

37 S. Gong, Q. Fu, Q. Wang, C. Yang, C. Zhong, J. Qin and D. Ma, Adv. Mater., 2011, 23, 4956.

38 C. Fan, Y. Chen, Z. Liu, Z. Jiang, C. Zhong, D. Ma, J. Qin and C. Yang, J. Mater. Chem. C, 2013, 1, 463.

39 Y. J. Cho and J. Y. Lee, J. Phys. Chem. C, 2011, 115, 10272.

40 D. Hu, P. Lu, C. Wang, H. Liu, H. Wang, Z. Wang, T. Fei, X. Gu and Y. Ma, J. Mater. Chem., 2009, 19, 6143.

41 M.-H. Tsai, H.-W. Lin, H.-C. Su, T.-H. Ke, C.-C. Wu, F.-C. Fang, Y.-L. Liao, K.-T. Wong and C.-I. Wu, Adv. Mater., 2006, 18, 1216.

42 T. Tsuboi, S.-W. Liu, M.-F. Wu and C.-T. Chen, Org. Electron., 2009, 10, 1372.

43 J. Ding, B. Zhang, J. Lu, Z. Xie, L. Wang, X. Jing and F. Wang, Adv. Mater., 2009, 21, 4983.

44 S. Shao, J. Ding, L. Wang, X. Jing and F. Wang, J. Am. Chem. Soc., 2012, 134, 20290.

45 Z. Ge, T. Hayakawa, S. Ando, M. Ueda, T. Akiike, H. Miyamoto, T. Kajita and M. Kakimoto, Adv. Funct. Mater., 2008, 18, 584.

46 S. Gong, Q. Fu, W. Zeng, C. Zhong, C. Yang, D. Ma and J. Qin, Chem. Mater., 2012, 24, 3120.

47 S.-J. Su, Y. Takahashi, T. Chiba, T. Takeda and J. Kido, Adv. Funct. Mater., 2009, 19, 1260.

48 J.-H. Jou, W.-B. Wang, S.-Z. Chen, J.-J. Shyue, M.-F. Hsu, C.-W. Lin, S.-M. Shen, C.-J. Wang, C.-P. Liu and C.-T. Chen, J. Mater. Chem., 2010, 20, 8411.

49 K. S. Yook, S. E. Jang, S. O. Jeon and J. Y. Lee, Adv. Mater., 2010, 22, 4479.

50 Y. J. Doh, J. S. Park, W. S. Jeon, R. Pode and J. H. Kwon, Org. Electron., 2012, 13, 586. 